\title{
Cost-Effectiveness Analysis of Nonoperative Management Versus Open and Laparoscopic Surgery for Uncomplicated Acute Appendicitis in Colombia.
}

Cesar Augusto Guevara-Cuellar ( $\sim$ cguevara@icesi.edu.co)

Universidad Icesi https://orcid.org/0000-0002-4412-0261

María Paula Rengifo-Mosquera

Icesi University Faculty of Health Sciences: Universidad ICESI Facultad de Ciencias de la Salud

Elizabeth Parody-Rúa

Couseling

\section{Research}

Keywords: cost-effectiveness, nonoperative management, open appendectomy, laparoscopic appendectomy, acute appendicitis

Posted Date: March 15th, 2021

DOI: https://doi.org/10.21203/rs.3.rs-296357/v1

License: () (i) This work is licensed under a Creative Commons Attribution 4.0 International License. Read Full License 


\section{Abstract}

Background

Traditionally, uncomplicated acute appendicitis (AA) has been treated with appendectomy. However, the surgical alternatives might carry out significant complications, impaired quality of life, and higher costs than nonoperative treatment. In consequence it is necessary to evaluate the efficiency of the different therapeutic alternatives in patients diagnosed with uncomplicated appendicitis.

Methods

We performed a model-based cost-effectiveness analysis comparing nonoperative management (NOM) with open appendectomy (OA) and laparoscopic appendectomy (LA) in patients otherwise healthy adults aged 18 years and older with a diagnosis of uncomplicated AA in the Colombian health system. The time horizon was five years. A discount rate of $5 \%$ was applied to both costs and outcomes. The health outcomes were quality-adjusted life years (QALYs). Costs were identified, quantified, and valorized from a payer perspective; therefore, only direct health costs were included. An incremental analysis was estimated to determine the incremental cost-effectiveness ratio (ICER). In addition, the net monetary benefit (NMB) was calculated for each alternative using a willingness to pay lower than a one gross domestic product. A deterministic and probabilistic sensitivity analysis was performed.

Results

LA presents a lower cost $(\$ 363 \pm 35)$ than OA $(\$ 384 \pm 41)$ and NOM $(\$ 392 \pm 44)$. NOM exhibited higher QALYs (3.3332 \pm 0.0276$)$ in contrast with LA (3.3310 \pm $0.057)$ and OA (3.3261 \pm 0.0707$)$. LA dominated the OA. The ICER between LA and NOM was $\$ 24000 / Q A L Y$. LA has a $52 \%$ probability of generating the highest NMB versus its counterparts, followed by NOM (30\%) and OA (18\%). There is a probability of 0.69 that laparoscopy generates more significant benefit than medical management. The mean value of that incremental NMB would be $\$ 93.7$ per patient.

Conclusions

LA is more likely to produce more significant monetary benefits than NOM and OA in uncomplicated AA. This feature becomes the most efficient alternative as long as the conditions for its adequate performance exist. However, NOM may be a more acceptable alternative from the patient's perspective or when only the OA option is available.

\section{Background}

Acute appendicitis (AA) is one of the most common causes of abdominal pain. The European Association for Endoscopic Surgery estimates this condition affects from 5.7 to 57 per 100000 people each year. The lifetime risk is about $16.3 \%$ in industrialized countries, (1) 8.6\% for men, and $6.7 \%$ for women in developing countries (2). Furthermore, the total medical costs associated with this condition oscillate between $\$ 5989$ and $\$ 6075$ per patient in developing countries $(3,4)$.. In Colombia, it is estimated that the cumulative costs generated by open (OA) and laparoscopic appendectomy (LA) are US\$65 753 and $\$ 66$ 425 , respectively, in 2013. Finally, complications can generate cumulative costs of approximately $\$ 297$ for OA and \$271 for LA in that period (5). Despite being a benign condition, its high incidence and risk of complications represent a significant financial burden for healthcare systems.

Traditionally, AA has been treated surgically. The surgical approach has been preferred because of the high success rate, eradication of the underlying cause, and the relatively low procedure's complexity (6). Indeed, around 300000 appendectomies are performed annually only in EEUU, being LA the preferred option (7). However, the technological restrictions, the cost of some supplies, and the lack of trained staff, are barriers to LA's wider adoption (8, 9). For this reason, a significant proportion of appendectomies are still performed through an open approach worldwide $(5,10)$. Nevertheless, OA presents a higher risk of complications such as infection of the surgical site, incisional hernias, abdominal pain, and obstructive symptoms.(11)

In addition to the above, some situations have questioned the traditional surgical management and propose alternative therapeutic approaches. Firstly, there are concerns about the safety of surgical treatment in high-risk surgical patients. Secondly, recent studies suggest that uncomplicated AA may be a condition with a high likelihood of spontaneous remission with supportive care alone (12). Finally, several well-designed controlled clinical studies have shown the potential benefits of nonoperative management (NOM). The most recent long-term Appendicitis Accuta Trial (APPAC) compared antibiotic versus surgical management. In this study, NOM presented a success rate of $72.7 \%$ within five years.(13) Additionally, several systematic reviews have reported clinical benefits of NOM versus surgical approach $(1,6,14-21)$.

A review of the literature shows that NOM brings certain advantages over appendectomy. These advantages include a significantly lower overall complication rate in the short term, a reduction of approximately $50 \%$ or more in costs, and a lower disability than surgery (3). Additionally, there are other variables in which no statistically significant difference has been found between the two alternatives, such as hospital stay length $(11,22)$. However, NOM has disadvantages, such as a significant probability of evolution to complicated appendicitis and recurrence, leading to incurring cost overruns. This dilemma requires to evaluate the long-term impact and economic implications of NOM of uncomplicated AA.

This study's objective was to evaluate the efficiency of NOM compared to OA and LA in patients diagnosed with uncomplicated AA in the Colombian health system.

\section{Methods}

A model-based cost-effectiveness analysis was conducted for estimating the efficiency of OA, LA, and NOM in the treatment of uncomplicated AA from the Loading [MathJax]/jax/output/CommonHTML/jax.js . The Colombian health system is based on a market mechanism regulated by the Ministry of Health. There are 
public and private entities responsible for the insurance and provision of health services. The primary sources of financing are the quotations of employees and employers, who finance the private contributory regime, and fiscal resources obtained through general taxes, which finance the public subsidized regime.

The national methodological guideline for economic evaluation was followed (23).

The time horizon was five years. This horizon was chosen because some late complications can occur during this period in patients managed with NOM (13) A discount rate of $5 \%$ was applied to both costs and outcomes. This rate is recommended for the methodological guidelines for economic evaluation in Colombia (23).

The hypothetic population evaluated by our model included otherwise healthy adults aged 18 years and older with a diagnosis of uncomplicated AA. Uncomplicated AA was defined as no evidence of inflammatory mass, phlegmon, abscess, or appendicolith in abdominal imaging.

The alternatives included surgical and medical options. The surgical procedures evaluated were OA and LA. The NOM includes clinical observation in the hospital for at least 72 hours, assessment by a surgeon, routine diagnostic aids, and antibiotics administration. The antibiotics regimen evaluated included ertapenem ( $1 \mathrm{gr} \mathrm{c} / 24 \mathrm{~h} \times 3$ days), levofloxacin $(500 \mathrm{mg} \mathrm{c} / 24 \mathrm{~h} \times 7$ days) + metronidazole ( $500 \mathrm{mg} \mathrm{c} / 8 \mathrm{~h} \times 7$ days). These alternatives were extracted from clinical literature (11). Besides, expert surgeons validated that those represent the routine clinical practice in our context. Other antibiotic regimens were not evaluated due to the absence of long-term clinical data.

The health outcomes were quality-adjusted life years (QALYS) according to the methodological guidelines. The utility and disutility weights were extracted from the Cost-Effectiveness Analysis Registry of the Tufts Medical Center (24). The QALYs were calculated by multiplying each event/state's utility by the length of time expressed in years.

A literature review was conducted to identify published model-based economic evaluations. Although four models were found, no one was employed in our economic evaluation because they evaluated complicated appendicitis, prophylactic appendectomy, and different length of hospital stay giving antibiotic therapy $(4,25-27)$. For this reason, a de novo decision model was designed.

Figure 1 displays the model structure. It was considered appropriate to use a decision tree because events in uncomplicated AA usually have a short duration and rapid resolution. See additional file 1: Table S1. Model parameters.

An expert surgeon carried out the model's face validity. The model was validated by comparing the current model results with different published models and available clinical data. We used a microsimulation for each of the alternatives evaluated to verify the model's internal validity.

The model's assumptions were as follows: I) The management of intra-abdominal abscess was the same regardless of the type of surgery. II) Death was not included because it has a very low probability $(<1 \%)(13)$. III) The incisional hernia and the enteric fistula were not considered because they are negligible for both surgical procedures ( $0.4 \%$ and $0.5 \%$ ) (28). IV) Abdominal sepsis was not included because of its very low incidence in uncomplicated AA (29). V) Postoperative ileus is managed within the same hospitalization without considerably affecting the quality of life.

Costs were identified, quantified, and valorized from a payer perspective; therefore, only direct health costs were included.

The identification and quantification of resources were obtained from clinical practice guidelines and an expert who validated them (6). Unit costs for diagnostic tests and surgical procedures were obtained from the national tariffs (30). The unitary costs for medications were obtained from the Sistema de Informacion de Medicamentos (31). Total cost was calculated by multiplying the unit cost by the units required of each resource. The costs were expressed US dollars at the current exchange rate (1 USD = COP 3478 ).

An incremental analysis was estimated to determine the incremental cost-effectiveness ratio (ICER).

This ratio is expressed mathematically in the following expression:

$$
I C E R=\frac{\text { Incrementalcost }_{\text {IncrementalQALYS }}}{\text { Incost }}=\frac{\text { Cost }_{A}}{Q A L Y_{B}-Q A L Y_{A}}
$$

In addition, the net monetary benefit (NMB) was calculated for each alternative. This benefit is mathematically expressed as follows:

$$
N M B=\Delta E \lambda-\Delta C
$$

$\Delta E$ indicates the incremental effect (i.e., the difference of QALYs between two alternatives), $\Delta C$ indicates the incremental cost, and $\lambda$ means the willingness to pay. The York Health Economic Consortium defines the NMB as "...a summary statistic that represents the value of an intervention in monetary terms when a willingness to pay threshold for a unit of benefit is known." (32). In consonance with national guidelines, the willingness-to-pay threshold was US\$ 6.667. This value represents the gross domestic product (GDP) per capita in Colombia.

A deterministic and probabilistic sensitivity analysis was performed. The deterministic analysis was univariate and multivariate and graphed in a tornado plot for the essential variables. The probabilistic sensitivity analysis (PSA) was performed with a Monte Carlo simulation with 10000 iterations. The distribution parameters are presented in additional file 2: Table S2. A patient-level simulation (i.e., microsimulation) was performed with 1000 trials to incorporate heterogeneity. For this purpose, random utility values were assigned to each trial when entering the model. Finally, a simulation with 100000 trials was performed to evaluate the effects on incremental cost in a hypothetical population with this number of patients.

Loading [MathJax]/jax/output/CommonHTML/jax.js Ith Pro 2020 software (TreeAge Software, Inc., USA).

Page 3/11 
This study did not require ethical approval because there was no participation of humans or animals.

\section{Results}

The deterministic incremental analysis is presented in Table 1. This analysis revealed that LA dominates OA. Contrastingly, the NOM produced 0.003 more QALYs per patient (discounted) than LA but at a higher discounted incremental cost (\$61 per patient). The ICER of \$24 000/QALY additional is above the willingness to pay 1GDP per capita in Colombia (\$6 667/QALY additional). Therefore, NOM would not be considered an efficient alternative for that willingness to pay.

Table 1

Incremental analysis of the alternatives in treatment for uncomplicated AA

\begin{tabular}{|c|c|c|c|c|c|c|c|c|c|}
\hline \multirow[t]{2}{*}{ Alternatives } & \multicolumn{5}{|c|}{ Undiscounted } & \multicolumn{4}{|c|}{ Discounted } \\
\hline & $\begin{array}{l}\text { Mean } \\
\text { costt }\end{array}$ & Incremental cost & $\begin{array}{l}\text { Mean } \\
\text { QALYs* }\end{array}$ & Incremental QALYs, & $\begin{array}{l}\text { ICER } \neq \\
\text { (\$/QALY) }\end{array}$ & $\begin{array}{l}\text { Mean } \\
\text { cost }\end{array}$ & Incremental cost & $\begin{array}{l}\text { Mean } \\
\text { QALYs }\end{array}$ & Incremental QALYs \\
\hline $\begin{array}{l}\text { Laparoscopic } \\
\text { appendectomy }\end{array}$ & 308 & & 4,9863 & & & 308 & & 4,1022 & \\
\hline $\begin{array}{l}\text { Open } \\
\text { appendectomy }\end{array}$ & 309 & 1 & 4,9795 & -96 & $\begin{array}{l}\text { Absolute } \\
\text { dominance }\end{array}$ & 309 & 1 & 4,0966 & $-0,0056$ \\
\hline \multirow{3}{*}{$\begin{array}{l}\text { Nonoperative } \\
\text { management }\end{array}$} & 415 & 106 & 4.9899 & 0.0104 & 10.192 & 369 & 60 & 4,1052 & 0,0085 \\
\hline & \multicolumn{5}{|c|}{ Undiscounted } & \multicolumn{4}{|c|}{ Discounted } \\
\hline & $\begin{array}{l}\text { Mean } \\
\text { cost }\end{array}$ & Incremental cost & $\begin{array}{l}\text { Mean } \\
\text { QALYs }\end{array}$ & Incremental QALYs, & ICER(\$/QALY) & $\begin{array}{l}\text { Mean } \\
\text { cost }\end{array}$ & Incremental cost & $\begin{array}{l}\text { Mean } \\
\text { QALYs }\end{array}$ & Incremental QALYs \\
\hline $\begin{array}{l}\text { Laparoscopic } \\
\text { appendectomy }\end{array}$ & 308 & & 4,9863 & & & 308 & & 4,1022 & \\
\hline $\begin{array}{l}\text { Nonoperative } \\
\text { management }\end{array}$ & 415 & 107 & 4.9899 & 0.0036 & 29.722 & 369 & 72 & 4,1052 & 0,003 \\
\hline
\end{tabular}

* QALYs: Quality-adjusted life-years

† Cost: US dollars ( 1 US dollar $=3478$ COP)

‡ ICER: Incremental cost effectiveness ratio

The deterministic sensitivity analysis revealed that NMB is influenced by the cost of LA, NOM, and hospitalization time in LA. It is observed that when the costs of LA range between $\$ 150$ and 350, the NMB ranges between $\$ 27153$ and \$26 910. Similarly, the analysis shows that a decrease in LA hospitalization time by two days could increase the NMB by only $0.05 \%$ (from $\$ 27041$ to $\$ 27055$ ). Finally, the reduction of medical management costs by $\$ 200$ produces an increase in NMB from \$26 908 to \$27 108. The tornado graph and the threshold analysis are available in the additional file 3 (figure S1-S3). These results show that the reduction in costs of LA could generate the most significant variability in NMB.

Table 2 presents the results of the probabilistic sensitivity analysis. The Monte Carlo simulation reveals that LA presents a lower cost (\$ 363 \pm 35$)$ than OA (\$ $384 \pm 41)$ and NOM (\$392 \pm 44$)$. On the other hand, NOM exhibited higher QALYs (3.3332 \pm 0.0276$)$ in contrast with LA (3.3310 \pm 0.057$)$ and OA (3.3261 \pm 0.0707). Histograms for each of these variables can be found in the additional file 3 (figure S4-S20). 
Table 2

Results of probabilistic sensitivity analysis

\begin{tabular}{|llll|}
\hline & Open appendectomy & Laparoscopic appendectomy & Nonoperative management \\
\hline Cost* (USD\$) & & 363 & 392 \\
\hline Mean & 384 & 35 & 44 \\
\hline Std Deviation & 41 & 295 & 264 \\
\hline Minimum & 295 & 359 & 389 \\
\hline Median & 377 & 359 & 635 \\
\hline Maximum & 573 & & 3,3332 \\
\hline QALYs $†$ & & 3,3310 & 0,0276 \\
\hline Mean & 3,3261 & 0,0570 & 2,8988 \\
\hline Std Deviation & 0,0707 & 2,4987 & 3,3417 \\
\hline Minimum & 2,3643 & 3,3417 & 3,3417 \\
\hline Median & 3,3417 & 3,3417 & \\
\hline Maximum & 3,3417 & & \\
\hline * Cost: US dollars (1 US dollar = 3 478 COP) & & \\
\hline + QALYs: Quality-adjusted life-years & & \\
\hline
\end{tabular}

The higher efficiency of LA was consistent when incorporating uncertainty into the model. The acceptability curve in Fig. 2 plots the proportion of iterations in which each alternative had the greater NMB for different willingness-to-pay. This graphic shows that LA has a $52 \%$ probability of generating the highest NMB versus its counterparts, followed by NOM (30\%) and OA (18\%). The choice of LA is not modified by greater or lesser willingness to pay or resource availability.

Figure 3 sets out the incremental NMB between LA and NOM (i.e., the subtraction of the NMB of the two alternatives) for a willingness to pay 1 GDP per capita. This graph shows a probability of 0.69 that laparoscopy generates more significant benefit than medical management. The mean value of that incremental NMB would be $\$ 93.7$ per patient. That mean value increases to $\$ 180$ if the willingness to pay increases to 3 GDP per capita. See additional file 3 (figure S21).

Simulation results with 100000 trials produced costs of \$36 $220164( \pm 3422719)$ with LA, \$38 374539 ( \pm 4030340$)$ with OA, and $\$ 38194731$ ( \pm 4451 123) with NOM. Thus, performing OA and NOM instead of LA results in over expenditures on average of \$2 154375 and 1974567 per 100000 patients. Histograms are in additional file 3 (S1-S8).

\section{Discussion}

Our study results show that LA has a high probability of producing higher NMB than OA and NOM in patients with uncomplicated AA with a willingness to pay less than 1 GDP capita.

The lower cost of LA could explain this higher benefit. Previous studies have shown that LA might have lower costs than the open approach (5, 33-36). This reduced cost is explained by the shorter length of hospital stay, quicker postoperative recovery, and the lower probability of postoperative complications. In this aspect, the results of our study are consistent with those reported in the literature.

Likewise, our model revealed that the costs of LA are lower than NOM. This result differs from other published economic evaluations, showing that NOM is cost saving compared to surgical alternatives. This difference could be explained by the different time horizons of these studies. Sippola et al. followed some participants in the APPAC study for one year (3). On the other hand, Wu et al. designed a decision model with a 1-year time horizon (25). By adopting a shorter time horizon, the costs of patients who will recur after the first year would not be estimated. Salminen et al. demonstrated that the percentage of people who underwent appendectomy could increase from $27-40 \%$ after the first year (13). Of these patients, almost $10 \%$ might recur with complicated appendicitis, which implies higher costs subsequently. Sceats et al. revealed that NOM was associated with higher abscess rates, readmission, and higher overall care costs (37). As long as the appendix remains, the risk of recurrence is latent.

LA might represent significant savings for the health care system. Our model estimated a mean value of more than 2 million savings for every 100000 LA performed instead of OA and more than 1 million compared to NOM. The probability of achieving these savings is greater than $64 \%$. This saving would represent $2.3 \%$ and $1.4 \%$ respectively of the total health expenditure for many people in Colombia (35). From a financial perspective, LA is the best option for the health system.

A meaningful reduction in the cost of the NOM could become a more efficient alternative than LA. According to our model, this objective would be attained by reducing NOM costs by $55 \%$. In this case, the main expense was represented by the antibiotic regimen. Potentially, the use of other lower-cost antibiotic regimens might improve the efficiency. Unfortunately, the lack of long-term comparative studies of antibiotic regimens is a limitation. 
On the other hand, NOM provided a minimal increase in QALYs than the surgical alternatives. Our model revealed that NOM provided 0.003 and 0.0086 QALYS more than LA and OA, respectively. That marginal health benefit is equivalent to having 1 and 3.1 days in perfect health compared to LA and OA. Among the factors that could explain these differences are the lower probability of adverse events, less pain, and shorter absence from work than surgical options. In addition to a significant proportion who do not present symptoms or recurrence (38). Another reason is the surgery could affect the quality of life for up to a month after being carried out (39).

Despite the above results, NOM of uncomplicated appendicitis might represent an efficient alternative in some situations. The first situation would be in case of lack of surgeons in some regions. In this case, the additional costs of transporting the patient to a center would result in LA not being the most efficient alternative. Also, the delay in the treatment would increase the risk of complications. The second situation is when the only option available is OA. This situation is frequent in hospitals where there is neither the technology nor the surgeons trained to perform LA. Two other possible situations would be in patients with high surgical risk or a collapse of the health system due to extreme public health situations (e.g., COVID). However, these two situations were not evaluated by our model.

Our economic evaluation has several limitations. Firstly, we considered a time horizon of five years only. This consideration might underestimate costs or overestimate QALYs in NOM because subsequent events are not quantified. Nevertheless, the incidence of this disease tends to decrease in the older population $(40,41)$. Secondly, our evaluation did not include an analysis by the patients' subgroup. Possibly, NOM may be a more efficient alternative in patients with high surgical risk. To incorporate heterogeneity in baseline health states, we performed a patient-level simulation with different utilities. In a particular manner, these microsimulations could partially reflect worse health states due to comorbidities. Finally, our model did not consider LA's learning curve and its impact on costs, postsurgical complications, or conversion to OA. The model also did not value capital costs (i.e., fiber optics, monitors) or some of the supplies needed to perform LA. Published studies show that these factors can increase costs and, therefore, could decrease this surgical approach's efficiency $(42,43)$.

Several issues remain to be clarified. The first one is about the probability of recurrence after five years and the impact on the quality of life and costs. On the other hand, it is mandatory quantifying the alternatives' efficiency in populations with high surgical risk or difficulty (e.g., obesity, pulmonary diseases). Finally, it is necessary to incorporate into the new evaluations the effect on the costs of the LA learning curve's efficiency.

\section{Conclusions}

LA is more likely to produce more significant monetary benefits than NOM and OA in uncomplicated AA. This feature becomes the most efficient alternative if the conditions for its adequate performance exist. However, NOM may be a more acceptable alternative from the patient's perspective or when only the OA option is available.

\section{Abbreviations}

AA: acute appendicitis; OA: open appendectomy; LA: laparoscopic appendectomy; NOM: nonoperative management; QALYs: quality-adjusted life years; ICER: incremental cost-effectiveness ratio; NMB: net monetary benefit.

\section{Declarations}

\section{Ethics approval and consent to participate.}

Not applicable.

\section{Consent for publication.}

Not applicable.

\section{Availability of data and materials.}

All data generated or analyzed during this study are included in this published article [and its supplementary information files].

\section{Competing interest.}

The authors declare that they have no competing interest.

\section{Funding}

This research did not receive any financial support.

\section{Authors' contributions}

Concept and design: CAG-C, MPR-M. Acquisition of data: CAG-C, EP-R, MPR-M. Analysis and interpretation of data: CAG-C, MPR-M. Drafting of the manuscript: CAG-C, EP-R, MPR-M. Critical revision of the paper for important intellectual content: CAG-C, EP-R, MPR-M. Statistical analysis: CAG-C, EP-R, MPR-M. Provision of study materials or patients: CAG-C, EP-R. Administrative, technical, or logistic support: CAG-C, EP-R. Supervision: CAG-C, EP-R. 
We thank to Doctor Alberto García, for his revision of the model structure.

\section{References}

1. Poon SHT, Lee JWY, Ka Man NG, Chiu GWY, Wong BYK, Foo CC, et al. The current management of acute uncomplicated appendicitis: Should there be a change in paradigm? A systematic review of the literatures and analysis of treatment performance. World J Emerg Surg. 2017;12(1):1-10.

2. Buitrago G, Junca E, Eslava-Schmalbach J, Caycedo R, Pinillos P, Leal LC. Clinical Outcomes and Healthcare Costs Associated with Laparoscopic Appendectomy in a Middle-Income Country with Universal Health Coverage. World J Surg [Internet]. 2019;43(1):67-74. Available from: https://doi.org/10.1007/s00268-018-4777-5

3. Sippola S, Grönroos J, Tuominen R, Paajanen H, Rautio T, Nordström P, et al. Economic evaluation of antibiotic therapy versus appendicectomy for the treatment of uncomplicated acute appendicitis from the APPAC randomized clinical trial. Br J Surg. 2017 Sep;104(10):1355-61.

4. Sugiura K, Suzuki K, Umeyama T, Omagari K, Hashimoto T, Tamura A. Cost-effectiveness analysis of initial nonoperative management versus emergency laparoscopic appendectomy for acute complicated appendicitis. BMC Health Serv Res. 2020 Nov;20(1):1019.

5. Ruiz-Patiño A, Rey S, Molina G, Dominguez LC, Rugeles S. Cost-effectiveness of laparoscopic versus open appendectomy in developing nations: a Colombian analysis. J Surg Res. 2018 Apr;224:33-7.

6. Di Saverio S, Podda M, De Simone B, Ceresoli M, Augustin G, Gori A, et al. Diagnosis and treatment of acute appendicitis: 2020 update of the WSES Jerusalem guidelines. World J Emerg Surg. 2020 Apr;15(1):27.

7. Perez N, Romero M. Infección del sitio operatorio de apendicectomías 2009. Rev Colomb Cir. 2009;24:23-30.

8. Choy I, Kitto S, Adu N, Okrainec A. Barriers to the uptake of laparoscopic surgery in a lower-middle-income country. Surg Endosc. 2013 Nov;27(11):400915.

9. Imran J, Ochoa A, Herrejon J, Ortiz C, Mijangos B, Madni T, et al. Barriers to adoption of laparoscopic cholecystectomy in a county hospital in Guatemala. Surg Endosc. 2019 Dec;33(12):4128-32.

10. Sartelli M, Baiocchi G, Di Saverio S, Ferrara F, Labricciosa F, Ansaloni L, et al. Prospective Observational Study on acute Appendicitis Worldwide (POSAW). World J Emerg Surg. 2018;13:19.

11. Salminen P, Paajanen H, Rautio T, Nordström P, Aarnio M, Rantanen T, et al. Antibiotic Therapy vs Appendectomy for Treatment of Uncomplicated Acute Appendicitis: The APPAC Randomized Clinical Trial. JAMA. 2015 Jun;313(23):2340-8.

12. Park H, Kim M, Lee B. Randomized clinical trial of antibiotic therapy for uncomplicated appendicitis. Br J Surg. 2017 Dec;104(13):1785-90.

13. Salminen P, Tuominen R, Paajanen H, Rautio T, Nordström P, Aarnio M, et al. Five-Year Follow-up of Antibiotic Therapy for Uncomplicated Acute Appendicitis in the APPAC Randomized Clinical Trial. JAMA. 2018 Sep;320(12):1259-65.

14. Gkegkes I, Minis E, lavazzo C. Effect of Caffeine Intake on Postoperative lleus: A Systematic Review and Meta-Analysis. Dig Surg. 2020;37(1):22-31.

15. Jaschinski T, Mosch C, Eikermann M, Neugebauer EAM. Laparoscopic versus open appendectomy in patients with suspected appendicitis: a systematic review of meta-analyses of randomised controlled trials. BMC Gastroenterol. 2015 Apr;15:48.

16. Abongwa HK, Cervellin G, Tarasconi A, Perrone G, Baiocchi G, Portolani N, et al. Antibiotics alone for uncomplicated acute appendicitis in high operative risk adult patients: Analytical review of RCTs and proposal of evidence based treatment decision. Acta Biomed. 2016 Jan;87(3):334-46.

17. Markides G, Subar D, Riyad K. Laparoscopic versus open appendectomy in adults with complicated appendicitis: Systematic review and meta-analysis. World J Surg. 2010;34(9):2026-40.

18. Ohtani H, Tamamori Y, Arimoto Y, Nishiguchi Y, Maeda K, Hirakawa K. Meta-analysis of the results of randomized controlled trials that compared laparoscopic and open surgery for acute appendicitis. J Gastrointest Surg Off J Soc Surg Aliment Tract. 2012 Oct;16(10):1929-39.

19. Talan DA, Krishnadasan A, R. A, K. P, A. M, G.J. M, et al. Antibiotics-First Versus Surgery for Appendicitis: A US Pilot Randomized Controlled Trial Allowing Outpatient Antibiotic Management. Ann Emerg Med [Internet]. 2017;70(1):1-11.e9. Available from: http://www.embase.com/search/results? subaction=viewrecord\&from=export\&id=L613978765\%0Ahttp://dx.doi.org/10.1016/j.annemergmed.2016.08.446

20. Ukai T, Shikata S, Takeda H, Dawes L, Noguchi Y, Nakayama T, et al. Evidence of surgical outcomes fluctuates over time: results from a cumulative metaanalysis of laparoscopic versus open appendectomy for acute appendicitis. BMC Gastroenterol. 2016 Mar;16:37.

21. Wang D, Dong T, Shao Y, Gu T, Xu Y, Jiang Y. Laparoscopy versus open appendectomy for elderly patients, a meta-analysis and systematic review. BMC Surg. 2019 May; 19(1):54.

22. Podda M, Gerardi C, Cillara N, Fearnhead N, Gomes CA, Birindelli A, et al. Antibiotic Treatment and Appendectomy for Uncomplicated Acute Appendicitis in Adults and Children: A Systematic Review and Meta-analysis. Ann Surg. 2019 Dec;270(6):1028-40.

23. IETS Instituto de Evaluación Tecnológica en Salud. Guidelines for the economic evaluation of healthcare technologies in Colombia: technical support documents. 2014.

24. Tufts Medical Center. Search the CEA Registry.

25. Wu JX, Dawes AJ, Sacks GD, Brunicardi FC, Keeler EB. Cost effectiveness of nonoperative management versus laparoscopic appendectomy for acute uncomplicated appendicitis. Surgery. 2015 Sep;158(3):712-21.

26. Schumm MA, Childers CP, Wu JX, Zanocco KA. Cost Saving of Short Hospitalization Nonoperative Management for Acute Uncomplicated Appendicitis. J Surg Res. 2020 Nov;255:77-85.

27. Newhall K, Albright B, Tosteson A, Ozanne E, Trus T, Goodney PP. Cost-effectiveness of prophylactic appendectomy: a Markov model. Surg Endosc. 2017 
28. Quah GS, Eslick GD, Cox MR. Laparoscopic appendicectomy is superior to open surgery for complicated appendicitis. Surg Endosc [Internet]. 2019;0(0):0. Available from: http://dx.doi.org/10.1007/s00464-019-06746-6

29. Talan DA, Saltzman DJ, DeUgarte DA, Moran GJ. Methods of conservative antibiotic treatment of acute uncomplicated appendicitis: A systematic review. J Trauma Acute Care Surg. 2019 Apr;86(4):722-36.

30. Instituto de Seguros Sociales. Tarifario ISS. 2001.

31. Ministerio de Salud de Colombia. Consulta Pública de Precios de Medicamentos en la Cadena de Comercialización - Circular 2 de 2012.

32. York Health Economics Consortium. Net Monetary Benefit - YHEC - York Health Economics Consortium.

33. Haas L, Stargardt T, Schreyoegg J. Cost-effectiveness of open versus laparoscopic appendectomy: a multilevel approach with propensity score matching. Eur J Heal Econ HEPAC Heal Econ Prev care. 2012 Oct;13(5):549-60.

34. Biondi A, Di Stefano C, Ferrara F, Bellia A, Vacante M, Piazza L. Laparoscopic versus open appendectomy: a retrospective cohort study assessing outcomes and cost-effectiveness. World J Emerg Surg. 2016;11(1):44.

35. Bank W. Current health expenditure per capita, PPP (current international \$) - Colombia | Data.

36. Minutolo V, Licciardello A, Di Stefano B, Arena M, Arena G, Antonacci V. Outcomes and cost analysis of laparoscopic versus open appendectomy for treatment of acute appendicitis: 4-years experience in a district hospital. BMC Surg. 2014 Mar;14:14.

37. Sceats LA, Ku S, Coughran A, Barnes B, Grimm E, Muffly M, et al. Operative Versus Nonoperative Management of Appendicitis: A Long-Term Cost Effectiveness Analysis. MDM policy Pract. 2019;4(2):2381468319866448.

38. Podda M, Poillucci G, Pacella D, Mortola L, Canfora A, Aresu S, et al. Appendectomy versus conservative treatment with antibiotics for patients with uncomplicated acute appendicitis: a propensity score-matched analysis of patient-centered outcomes (the ACTUAA prospective multicenter trial). Int $J$ Colorectal Dis. 2021 Jan;

39. Koumarelas K, Theodoropoulos GE, Spyropoulos BG, Bramis K, Manouras A, Zografos G. A prospective longitudinal evaluation and affecting factors of health related quality of life after appendectomy. Int J Surg. 2014;12(8):848-57.

40. Kraemer M, Franke C, Ohmann C, Yang Q. Acute appendicitis in late adulthood: incidence, presentation, and outcome. Results of a prospective multicenter acute abdominal pain study and a review of the literature. Langenbeck's Arch Surg. 2000 Nov;385(7):470-81.

41. Golz RA, Flum DR, Sanchez SE, Liu X, Donovan C, Drake FT. Geographic Association Between Incidence of Acute Appendicitis and Socioeconomic Status. JAMA Surg. 2020 Apr;155(4):330-8.

42. DeMare AM, Luehmann NC, Kawak S, Abbott EE, Long J, Akay B, et al. Cost-Effective Approach to the Laparoscopic Appendectomy: Balancing Disposable Instrument Cost With Operative Time. Am Surg. 2020 Jun;86(6):715-20.

43. Malhotra L, Pontarelli EM, Grinberg GG, Isaacs RS, Morris JP, Yenumula PR. Cost analysis of laparoscopic appendectomy in a large integrated healthcare system. Surg Endosc. 2021 Jan;

\section{Figures}




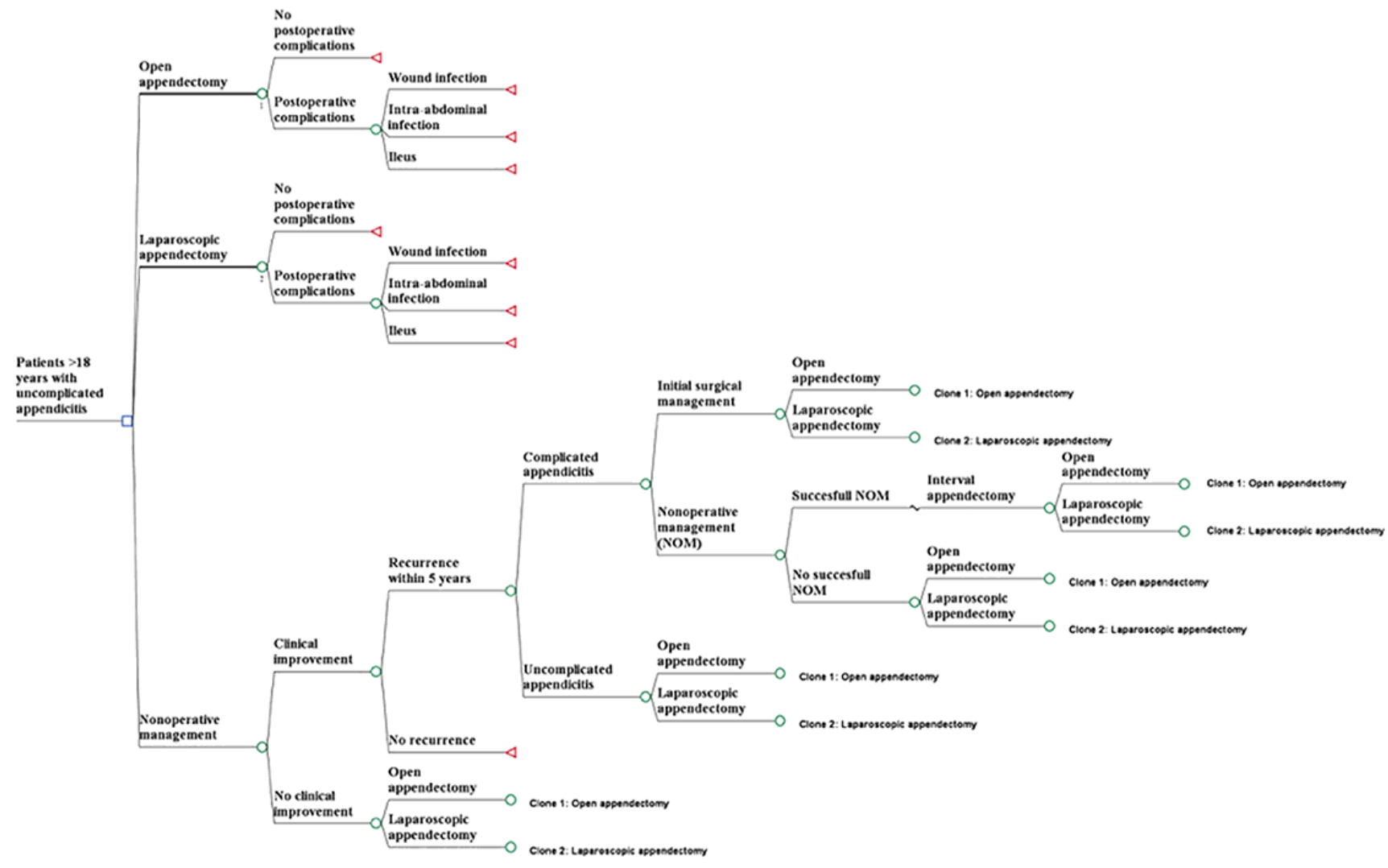

\section{Figure 1}

Displays the model structure. It was considered appropriate to use a decision tree because events in uncomplicated AA usually have a short duration and rapid resolution. See additional file 1: Table S1. Model parameters. 


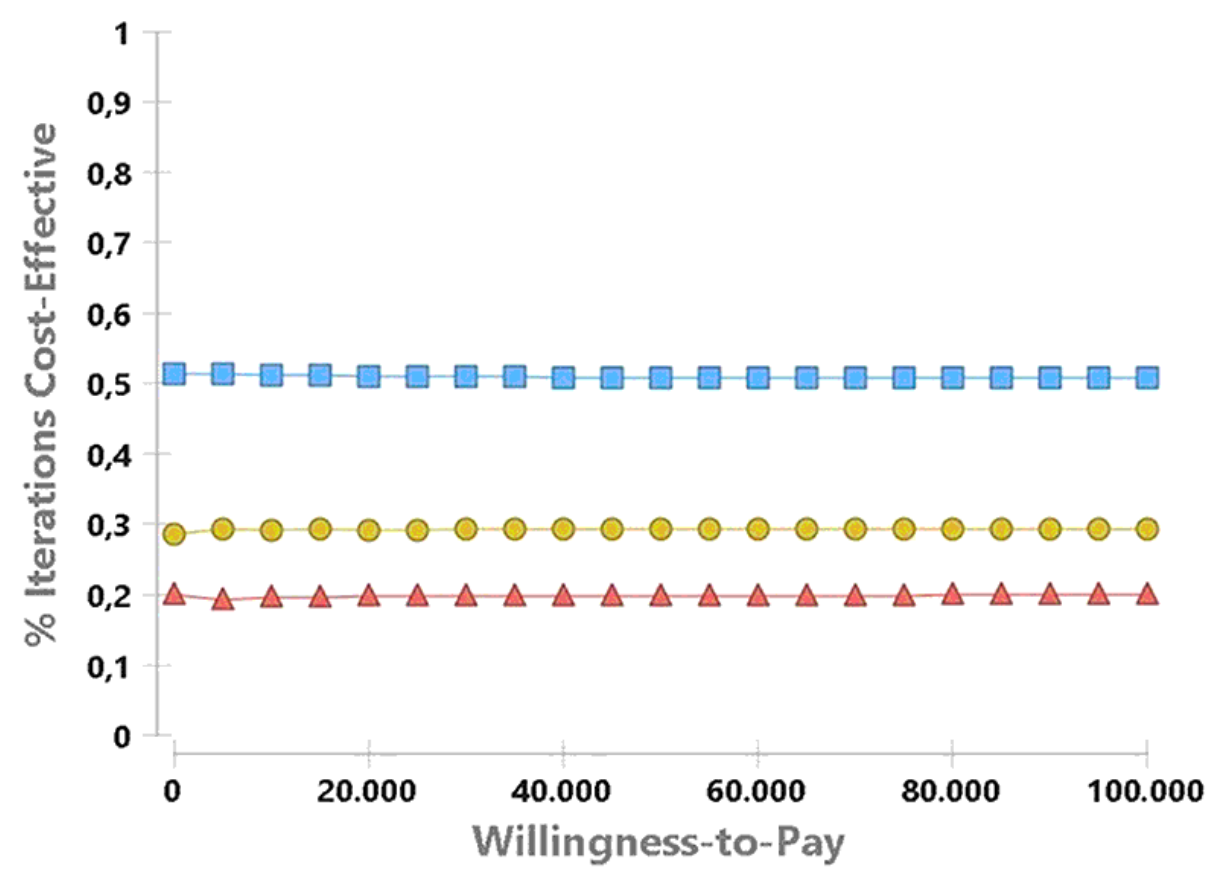

\section{Laparoscopic appendectomy}

$\triangle$ Nonoperative management

Open appendectomy

\section{Figure 2}

Plots the proportion of iterations in which each alternative had the greater NMB for different willingness-to-pay. This graphic shows that LA has a $52 \%$ probability of generating the highest NMB versus its counterparts, followed by NOM (30\%) and OA (18\%). The choice of LA is not modified by greater or lesser willingness to pay or resource availability.

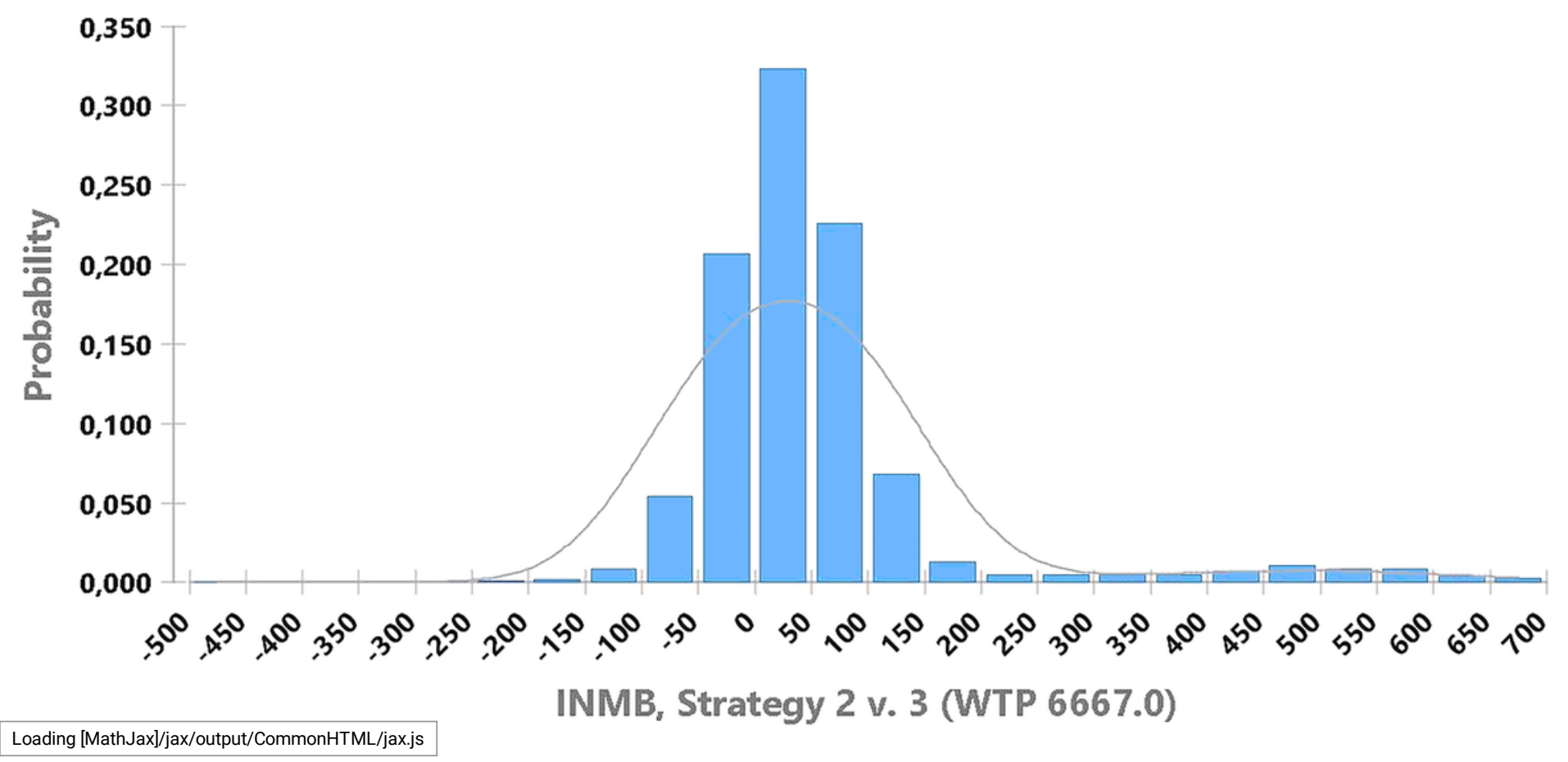


Figure 3

Sets out the incremental NMB between LA and NOM (i.e., the subtraction of the NMB of the two alternatives) for a willingness to pay 1 GDP per capita. This graph shows a probability of 0.69 that laparoscopy generates more significant benefit than medical management. The mean value of that incremental NMB would be $\$ 93.7$ per patient. That mean value increases to $\$ 180$ if the willingness to pay increases to 3 GDP per capita. See additional file 3 (figure S21).

\section{Supplementary Files}

This is a list of supplementary files associated with this preprint. Click to download.

- Additionalfile1.pdf

- Additionalfile2.pdf

- Additionalfile3.pdf 